\title{
Extracellular Enzymes of Endophytic Fungi Hosted Salt Marsh Plants in the South Eastern, Algeria
}

\author{
Wassima Lakhdari ${ }^{1,2, a)}$, Randa Mlik ${ }^{1}$, Hamida Hammi ${ }^{1}$, Ibtissem Benyahia ${ }^{3}$, Nour Elhouda \\ Mekhadmi ${ }^{4}$, Mohammed Berrekbia ${ }^{1}$, Sofiane Gheriani ${ }^{1}$ and Abderrahmene Dehliz ${ }^{1}$ \\ ${ }^{I}$ National Institute of Agronomic Research of Algeria, Station of Sidi Mehdi, Touggourt, 30200, Algeria. \\ ${ }^{2}$ Biology Department, Faculty of Life and Nature Sciences, Valcore Laboratory, University of Boumerdes, Algeria. \\ ${ }^{3}$ Department of Chemistry, Faculty of Mathematics and Material Sciences, Laboratory of Biogeochemistry and Desert \\ environments, University of Kasdi Merbah, Ouargla, Algeria. \\ ${ }^{4}$ Biology Department, University of El-Oued, Algeria. \\ ${ }^{a)}$ Corresponding Author: lakhdariwassima@yahoo.fr
}

Received : $12 / 10 / 2021$

Acceptance : $26 / 11 / 2021$

Available online: $31 / 12 / 2021$

\begin{abstract}
Endophyte microorganisms have great biotechnological interest, with features applicable to different areas and are potentially useful in agriculture. In the current study, the most dominant and representative endophytic fungal species of seven halophytic plants prevalent in the southeastern Algeria, Touggourt, were screened for their ability to produce four extracellular enzymes namely: cellulase, amylase, laccase, and lipase. Zygophyllum album came first by hosting diverse endophytic species among all the tested plants with eight species followed by Tamarix boveana and Limoniastrum guyonianum (46.66\%) as well as Phragmites communis with $40 \%$ and Haloxylon articulatum and Aeluropus littoralis with $33.33 \%$. Unlike J. effusus, it was the less diverse plant where only three species (20\%) were identified. In term of enzymatic activities of the selected fungi, the two species of Chaetomium presented cellulase, amylase and lipase activity. Unlike, Trichoderma harzianum involved in lipase, Ulocladium sp. in cellulase, Bipolaris sp. and Botryostimphylium sp. in Amylase. Unlike, the two species of Chaetomium involved in cellulase, amylase and lipase. On the other hand, no enzyme activity was recorded in the colonies of Fusarium sp.
\end{abstract}

Keywords. Halophyte, endophytic fungi, enzyme activity, cellulase, Sahara, Algeria.

\section{INTRODUCTION}

Endophytes are microorganisms that grow intracellularly for all or part of their life cycle in plants tissues, without causing disease to the host [1] where they protect their hosts against insect pests and pathogenic microorganisms and provide several benefits to the host plant [2,3]. However, these agents are known to produce metabolites such as alkaloids, terpenoids, steroids, quinones, iso-coumarin derivatives, flavanoids, phenols, phenolic acids, and peptides. In recent years, considerable attention has been given to the screening, isolation, and characterization of new bioactive secondary metabolites from endophytic fungi and metabolites with potential for use in industry, agriculture, and medicine [4-13]. Several plants were screened for their associated endophytic fungi and the capacity to show their enzymatic potentials. Whereas, enzymes are potential biocatalysts for a large number of reactions. Microorganisms represent a viable alternative source of enzymes, as they may be cultured in large quantities within short time frames by fermentation, are biochemically diverse, and are amenable to genetic manipulation [14]. Fungal endophytes produce several extracellular enzymes, such as pectinases, cellulases, lipases, amylases, laccases, and proteinases. Moreover, fungal enzymes play a key role in biodegradation and hydrolysis, mechanisms of significant importance in protection against invading pathogens, besides being crucial in obtaining nutrition from the host plant [15]. Indeed, their principal functions comprise hydrolysis of food substances and defense against pathogens [16]. Thus, these endophytic fungi may have an important ecological role for the survival of halophytes. On the other hand, the endophytic fungi of the Saharan region in our country still unexplored, where the extensive collection of fungi in unexplored areas remains a research priority [17].

Therefore, we sought to screen, as first data, the diversity of endophytic fungi presents in some halophytic plants, grown spontaneously in the southeastern Algeria (Sahara), to assess their biotechnological potential as producers of extracellular cellulase, laccase, amylase, and lipase. 


\section{MATERIAL AND METHODS}

\section{- Sampling Site}

The present work was carried out at the southeastern Algeria in the region of Touggourt. This region is located at the valley of Wadi Righ that extended from two provinces, Ouargla from the South and El Oued from the North. It is crossed by the Righ canal which serves to evacuate sewage of agglomerations and drainage of palm groves towards the big Chott of Merrouane. Indeed, a slope is recorded, from an altitude of 70m at Temacine for the highest point $-39 \mathrm{~m}$ at El Meghaï for the lowest point, that make the flow of water easier toward this point. Climatic data of study area show that the valley of Wadi Righ enjoys a Saharan climate that is characterized by a warm summer and a temperate winter. The max temperature was noted in August with a monthly average of $33{ }^{\circ} \mathrm{C}$ and the min was in January with $9{ }^{\circ} \mathrm{C}$. The humidity of the air is low, registering only an annual average of about $48 \%$. Precipitations are rare and random not exceeding $17 \mathrm{~mm}$ in the rainiest month well the different areas of our region are characterized even by saline or high saline soil [18].

\section{- Isolation and Identification of Endophytic Fungi}

According to precedent investigations on the ethnobotanic study remains the grown spontaneous and medicinal plants in the southeastern Algeria [19], seven selected plants from different areas, namely Zygophyllum album, Haloxylon articulatum, Tamarix boveana, Juncus effusus, Aeluropus littoralis, Phragmites communis, and Limoniastrum guyonianum were collected from the region of Touggourt, southeastern Algeria. Samples were collected in sterile polyethylene bags, closed by rubber band and transfer to the laboratory until plating. Leaves and branches were cut into small pieces with $1 \mathrm{~cm}$ long and sterilized in series with $70 \%$ ethanol for 1 min, $1.0 \%$ sodium hypochlorite $(\mathrm{NaClO})(\mathrm{v} / \mathrm{v})$ for $1 \mathrm{~min}$ and further cleaned by passing through two sets of sterile distilled water. The sterile samples were placed on plate, in the reason of five fragments per dish with 5 dishes for each plant, containing water agar (WA), Potato-Carrot (PCA), and oat meal agar (OMA). The parafilm wrapped petri dishes were incubated at $25 \pm 2^{\circ} \mathrm{C}$ till the fungal mycelia starts growing from the samples.

\section{- Enzyme Activity}

The ability of endophytic fungi to produce cellulase, laccase, amylase, and lipase were qualitatively assessed on specific indicative solid media. The isolates were transferred, to $5 \mathrm{~mm}$ mycelial plugs, on the center of the Petri dishes containing the solid medium with specific substrates to each enzyme described by [20].

\section{- Cellulase}

For cellulolytic activity, the isolates were grown on yeast extract peptone agar medium $(0.1 \mathrm{~g}$ yeast extract, $0.5 \mathrm{~g}$ peptone, $16 \mathrm{~g}$ agar, $1000 \mathrm{ml}$ distilled water) amended with $0.5 \% \mathrm{Na}$-carboxymethyl cellulose and then incubated. The plates were flooded with $0.1 \%$ Congo red and distained with $1 \mathrm{M}$ sodium chloride for $15 \mathrm{~min}$. The observed clear halo around the colony indicates the cellulose activity.

\section{- Laccase}

The activity of Laccase was determined by growing the selected isolates in Czapek-Dox medium ( $3 \mathrm{~g}$ NaNO3, $1 \mathrm{~g}$ K2HPO4, 0.5g MgSO4.H2O, 0.5g KCl, 30g Sucrose, 0.01g FeSO4, 15g Agar). After 3-5 days of incubation, the fully formed cultures were flooded with $0.2 \mathrm{~g}$ of Bromophenol blue. The presence of halo around the colony indicates the activity of laccase.

\section{- Amylase}

The activity of Amylase was determined by inoculating the selected isolates in GYP agar medium (1g glucose, $0.1 \mathrm{~g}$ yeast extract, $0.5 \mathrm{~g}$ peptone, $16 \mathrm{~g}$ agar, $1000 \mathrm{ml}$ distilled water, $\mathrm{pH} 6$ ) with $2 \%$ soluble starch. After 3-5 days of incubation, the fully formed cultures were flooded with Lugol solution ( $1 \%$ iodine in $2 \%$ potassium iodide). The visualized clear halo around the colony indicates the activity of Amylase. 


\section{- Lipase}

The activity of Lipase was observed by growing on the peptone agar media (10g peptone, $5 \mathrm{~g} \mathrm{NaCl}, 0.1 \mathrm{~g} \mathrm{CaCl} 22 \mathrm{H}$ $2 \mathrm{O}, 16 \mathrm{~g}$ agar, $1000 \mathrm{ml}$ distilled water, $\mathrm{pH}$ 6). For the sterilized peptone agar culture media, the Tween 20 was previously sterilized and added in a final concentration of $1 \%(\mathrm{v} / \mathrm{v})$. This media was inoculated with the isolates and incubated. The observation of halos around the colony confirmed the activity of Lipase.

\section{- Relative Enzyme Activity (RA)}

Fresh samples were used for enzyme assays whenever possible in order to ensure that the enzyme activity was maximal [21]. Each replicate was examined for the presence of a clear zone around the colony, and the diameters of the colony and of the clear zone (activity zone) were measured. The measurement was repeated in two mutually orthogonal dimensions, and the mean value calculated. The 'relative enzyme activity' (RA) was calculated using the following formula:

$$
\text { Relative enzyme activity }=(\text { Clear zone diameter- Colony diameter }) / \text { Colony diameter }
$$

Isolates exhibiting an RA of [1.0 were classified as having 'significant activity' [22,23].

\section{RESULTS}

\section{- Isolation and Identification of Endophytic Fungi}

A total of 15 endophytic fungi (Table1) were isolated and identified from soil, leaves and stems of the seven selected spontaneous plants i.e., Trichoderma harzianum, Ulocladium sp., Cheatomium atrobruneum, Chaetomium sp., Aspergillus flavus, A. niger, A. nidulans, Fusarium sp., Alternaria sp., Lasiodiplodia sp., Bipolaris sp., Stimphyllium sp., Botryostimphyllium sp., Cladosporium sp., Penicillium sp.

Seven species of these fungi were subjected to extracellular enzyme production in solid media (Table 1). Among all the isolated fungi, T. harzianum was the most recorded where it appears in all the parts of all the chosen plants, followed by the two species of Chaetomium with a rate of 8 to $32 \%$, unlike the other fungi that identified in one to three plants with a rate between 4 to $12 \%$ (Table 1). In term of plants, Z. album came first by hosting diverse endophytic species among all the tested plants with eight species of endophytic fungi, followed by T. boveana and L. guyonianum (46.66\%) as well as $P$. communis with $40 \%$ and $H$. articulatum and A. littoralis with $33.33 \%$. Unlike J. effusus, it was the less diverse plant where only three species $(20 \%)$ were identified.

TABLE 1. Endophytic fungi isolated from selected spontaneous plants.

\begin{tabular}{cccccccc}
\hline & Z. album & H. articulatum & T. boveana & J. effusus & A. littoralis & P. communis & L. guyonianum \\
\hline Trichoderma harzianum & 40 & 28 & 56 & 52 & 24 & 20 & 44 \\
Ulocladium sp. & 8 & - & 12 & - & - & - & - \\
Chaetomium atrobruneum & 20 & 32 & - & - & - & 32 & 8 \\
Chaetomium sp. & 20 & 28 & - & - & - & 28 & 12 \\
Aspergillus flavus & - & 8 & 20 & - & - & - & - \\
A. niger & 4 & 4 & 12 & 4 & - & - & - \\
A. nidulans & - & - & - & - & - & 4 & - \\
Fusarium sp. & - & - & - & - & 4 & - & - \\
Alternaria sp. & - & - & 8 & - & 4 & - & - \\
Lasiodiplodia sp. & 4 & - & - & - & 4 & - & - \\
Bipolaris sp. & - & - & - & - & - & 4 & - \\
Stimphyllium sp. & - & - & 4 & - & - & - & 4 \\
Botryostimphyllium sp. & - & - & - & - & 4 & - & - \\
Cladosporium sp. & 4 & - & 4 & - & - & - & 4 \\
Penicillium sp. & 4 & - & - & 4 & - & 4 \\
\hline
\end{tabular}

\section{- Enzyme Assay}

In our present investigation, 7 endophytic fungal isolates were screened for the presence of extracellular enzymes such as Cellulase, Laccase, Amylase, and Lipase which were grown on a specific medium discussed earlier in materials and methods. There is a considerable variation in the production of extracellular enzymes by the endophytic fungal isolates (Table 2). 
Whereas, the enzyme assay showed that only two species from all the isolated fungi have an enzymatic activity (Table 2). In first place, the two species of Chaetomium presented cellulase, amylase and lipase activity. Unlike, $T$. harzianum involved in lipase, Ulocladium sp. in cellulase, Bipolaris sp. in Amylase and Botryostimphylium sp. in amylase (Table 2). On the other hand, no enzyme activity was recorded in the colonies of Fusarium sp.

The results indicated that extracellular secretion of lipase by $T$. harzianum was observed and enzyme was detected noting that the relative enzyme activity of this fungus was $0.51 \mathrm{~mm}$. On the other hand, Cellulase $(0.29$ and $0.38 \mathrm{~mm})$, amylase $(0.4$ and $0.39 \mathrm{~mm})$ and lipase $(0.31$ and $0.29 \mathrm{~mm})$ activities were followed by the two species of Chaetomium. Also, the species of Bipolaris and Botryostimphyllium have shown an amylase activity with a diameter of 0.31 and 0.55 $\mathrm{mm}$, respectively.

TABLE 2. Relative enzyme activity in selected fungi.

\begin{tabular}{ccccc}
\hline & Cellulase & Laccase & Amylase & Lipase \\
\hline T. harzianum & - & - & - & 0.51 \\
C. atrobruneum & 0.29 & - & 0.4 & 0.31 \\
Chaetomium sp. & 0.38 & - & 0.39 & 0.29 \\
Ulocladium sp. & 0.43 & - & - & - \\
Fusarium sp. & - & - & - & - \\
Bipolaris sp. & - & - & 0.1 & - \\
Botryostimphyllium sp. & - & - & 0.55 & - \\
\hline
\end{tabular}

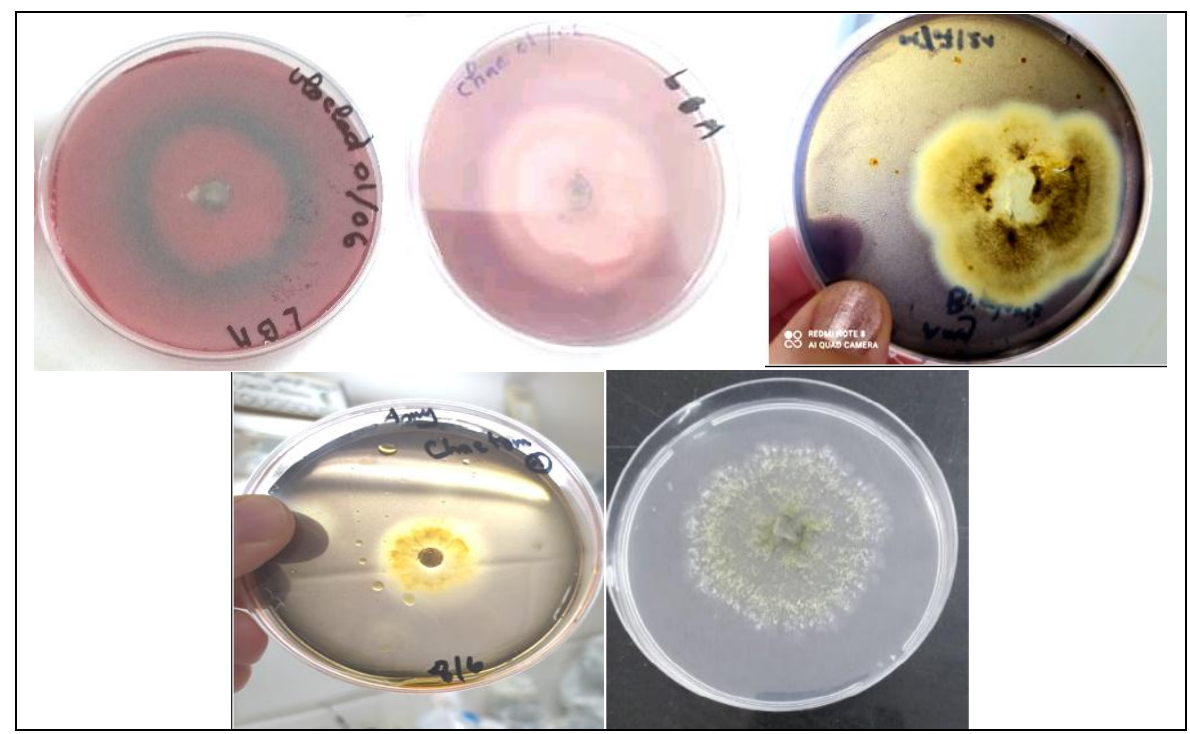

FIGURE 1. Some tested fungi with enzymatic activities.

\section{DISCUSSION}

Few studies, unless endophytic bacteria, were conducted in several countries on the isolation of endophytic fungi from different halophytic plants as well as their enzymatic activity. For this, our investigation was based on the diversity of endophytic fungi from some spontaneous halophytic plants collected from our region (Algerian Sahara).

The present study allowed as to isolate and identify 15 endophytic species from the seven chosen plants whereas $T$. harzianum was the most frequent recorded in all the parts of all the selected plants, followed by the two species of Chaetomium and A. niger, A. flavus, Cladosporium sp., and Penicillium sp. Unlike, the rest of isolated fungi, they were recorded in only one plant. In term of plants, Z. album was the most divert species in all the tested plants with eight species of endophytic fungi, followed by $L$. guyonianum $(7$ species) and $P$. communis and $H$. articulatum with 6 species. No studies have been reported before on the isolation of endophytic fungi, unless bacteria, from the selected plants neither in our country nor in this region. However, the results of the current study showed that every plant has presented different community of these microorganisms, where the eight obtained fungi in Z. album didn't find before in this species. Concerning the isolates in Juncus effuses, only two species were found i.e., T. harzianum and Penicillium sp. Other species from the same genus Juncus trifidus tested before by [24], revealed the isolation of 11 species of endophytic fungi from this spontaneous plant where Penicillium sp. was recorded. 
On the other hand, T. littoralis presented five species of endophytic fungi. Also, Tarroum et al. [25] have isolated six endophytic fungi from the same plant where Alternaria tenuissima was among these fungi. Whereas, Gashgari et al. [26] have identified 275 isolates belonging to 23 species and 14 genera were obtained from stem and root segments from seven medicinal plants, where Tamarix nilotica showed the highest endophytic diversity with a relative frequency of $27.27 \%$, followed by Cressa cretica with a relative frequency of $19.27 \%$. therefore, Bickford et al. [27] noted that the functional role of the isolated endophytes is not yet known, but one genus isolated here (Stagonospora) has been reported to enhance Phragmites growth. Understanding the diversity and functions of Phragmites endophytes may provide targets for control measures based on disrupting host plant/endophyte interactions. Also, Soares et al. [28] suggest that endophytes play a role in increasing the capacity of Phragmites australis to grow in high salinity soils, probably contributing to invasion in saline environments.

In another study isolating the endophytic fungi from halophytic plants (Arthrocnemum macrostachum, Halocnemum strobilecium, Limonastrum monopetalum, Zygophyllum album, Z. simplex, Tamarix nilotica, Zilla spinosa and Z. coccineum) from the Red Sea Coast of Egypt, Penicillium chrysogenum (45\%), Alternaria alternata (27\%) and Cladosporium cladosporioides (27\%) were the most frequent species [29].

Concerning the enzymatic activity, the obtained results in the current work showed that the endophytic fungal isolates came first by showing high amylase production activity in comparison with other enzymes. Firstly, $T$. harzianum showed only lipase activity, unlike, [30] have detected cellulase and xylanase activities from different strains of Trichoderma species (Trichoderma harzianum and T. Harzianum Th-azad) and T. viride 01PP Therefore, the genus Fusarium didn't show any enzymatic activity. Unlike other studies, where the lipolytic activity of some of these taxa, like Fusarium, has been reported before [15,31,32].

Concerning the genus Chaetomium, it is a saprobic fungus belonging to Ascomycota with high capability of degrading plant materials; it grows well and decomposes cellulose very rapidly, producing thermostable cellulases [33]. Studies have been conducted on various Chaetomium species such as Chaetomium cellulolyticum, C. erraticum, C. fusisporale, C. globosum, and C. thermophile to investigate their cellulolytic ability, localization, multiplicity, and characteristics of cellulase components.

Our results on the lipase enzyme activity, T. harzianum showed a relative enzyme activity of $0.51 \mathrm{~mm}$. Bhale and Rajkonda [34] found that Trichoderma species showed different extracellular enzyme activities where lipase activity was shown with a diameter zone measured from 25 to $31 \mathrm{~mm}$. Also, Abdel-Azeem and Salem [35] found that Chaetomium globosum measured about $40 \mathrm{~mm}$ color zone diameter and $55 \mathrm{~mm}$ growth colony diameter on the 7th day of cultivation. On the other hand, our results are similar to those found by Abdel-Azeem et al. [36] where all the isolates of Chaetomium globosum screened for potential enzymes showed amylolytic, cellulolytic, and proteolytic activities.

\section{CONCLUSION}

The results described here showed that every genus of these fungi has a specific enzyme activity as well as their capacity to produce different quantities. Thus, the present study demonstrates the importance of these endophytic fungi to the plant hosts and their role in the phytosanitary, the protection and the enhancement of these plants that are in association with them

\section{ACKNOWLEDGMENTS}

The present work was supported and funded by the social economic partner of SINAL, Oran (Algeria) in collaboration with the General Directorate of Scientific Research and Technological Development (DGRSDT) as part of a mixed research team's project, conducted with the National Institute of Agronomic Research of Algeria (INRAA).

\section{REFERENCES}

[1] Petrini O. (1991). Fungal endophytes of tree leaves. In: Andrews JH, Hirano SS, editors. Microbial Ecology of leaves. New York: Springer. 179-197.

[2] Azevedo J. L., Maccheroni J.r.W., Pereira J. O. \& Araújo W. L. (2000). Endophytic microorganisms: a review on insect control and recent advances on tropical plants. Electron J Biotechnol., 3, 1, 15-6.

[3] Sudha V., Govindaraj R., Baskar K., Al-Dhabi N. A., Duraipandiyan V. (2016). Biological properties of endophytic fungi. Braz Arch Biol Technol. 59: e16150436.

[4] Tan R. X., Zou W.X. (2001). Endophytes: a rich source of functional metabolites. Nat Prod Rep. 18: 448-59.

[5] Strobel G. A. (2003). Endophytes as sources of bioactive products. Microbes and Infection. 5: 535-44.

[6] Strobel G., Daisy B., Castillo U., Harper J. (2004). Natural products from endophytic microorganisms. J Nat Prod. 67 (2): 257-68. 
[7] Maria G. L., Sridhar K. R., Raviraja N. S. (2005). Antimicrobial and enzyme activity of mangrove endophytic fungi of southwest coast of India. Journal of Agricultural Technology.

[8] Rajamanikyam M., Vadlapudi V., Upadhyayula S. M. (2017). Endophytic fungi as novel resources of natural therapeutics. Braz Arch Biol Technol. 60: 1-7.

[9] Dutta D., Puzari K. C., Gogoi R., Dutta P. (2014). Endophytes: exploitation as a tool in plant protection. Braz Arch Biol Technol. 57, 5, 621-29.

[10] Kusari S., Singh S., Jayabaskaran C. (2014). Rethinking production of Taxol® (paclitaxel) using endophyte biotechnology. Trends Biotechnol., 32, 6, 304-11.

[11] Nisa H., Kamili A. N., Nawchoo I. A., Shafi S., Shameem N., Bandh A. S. (2015). Fungal endophytes as prolific source of phytochemicals and other bioactive natural products: a review. Microb Pathog., 82, 50-9.

[12] Qadri M., Nalli Y., Jain S. K., Chaubey A., Ali A., Strobel G. A., et al. (2017). An insight into the secondary metabolism of Muscodor yucatanensis: small-molecule epigenetic modifiers induce expression of secondary metabolism-related genes and production of new metabolites in the endophyte. Microb Ecol. 73 (4): 954-65.

[13] Ding C. H., Wang Q. B., Guo S., Wang Z. Y. (2018). The improvement of bioactive secondary metabolites accumulation in Rumex gmelini Turcz through co-culture with endophytic fungi. Braz J Microbiol., 49, 2, 362-69.

[14] Anbu P., Gopinath S. C. B., Cihan A. C. \& Chaulagain B. P. (2013). Microbial enzymes and their applications in industries and medicine. BioMed.

[15] Sunitha V. H., Nirmala Devi D., Srinivas C. (2013). Extracellular Enzymatic Activity of Endophytic Fungal Strains Isolated from Medicinal Plants. World Journal of Agricultural Sciences. 9 (1): 01-09.

[16] Desire M. H., Bernard F., Forsah M. R., Assang C. T., et al. (2014). Enzymes and qualitative phytochemical screening of endophytic fungi isolated from Lantana camara Linn. leaves. J. Appl. Biol. Biotechnol., 2, 1-6.

[17] Abdel-Azeem A. M. (2010). The history, fungal biodiversity, conservation, and future perspectives for mycology in Egypt. IMA Fungus, 1, 2, 123-142.

[18] Lakhdari W., Dehliz A., Mlik R., Benlamoudi W., Hammi H., Fathallah R., Benyahia I., Mekhadmi N. E., Acheuk F., Ouargli D. (2020). Euphorbia guyoniana Ethanolic Extract Efficiency Against Tomato Leaf Miner in Southeastern Algeria. Research Journal of Medicinal Plants. 14: 1-7.

[19] Lakhdari W., Dehliz A., Acheuk F., Mlik R., Hammi H., Doumandji-Mitiche B., Gheriani S., Berrekbia M., Guermit K., Chergui S. (2016). Ethnobotanical study of some plants used in traditional medicine in the region of Oued Righ (Algerian Sahara). Journal of Medicinal Plants Studies, 4, 2, 204-211.

[20] Amirita A., Sindhu P., Swetha J., Vasanthi N. S. \& Kannan K. P. (2012). Enumeration of endophytic fungi from medicinal plants and screening of extracellular enzymes. World Journal of Science and Technology, 2, 2, 13-19.

[21] German D. P., Weintraub M. N., Grandy A. S., Lauber C. L., Rinkes Z. L., Allison S. D. (2011). Optimization of hydrolytic and oxidative enzyme methods for ecosystem studies. Soil Biol Biochem., 43, 1387-1397.

[22] Duncan S. M., Minasaki R., Farrell R. L., Thwaites J. M., Held B. W., Arenz B. E., Jurgens J. A., Blanchette R. A. (2008). Screening fungi isolated from historic Discovery Hut on Ross Island, Antarctica for cellulose degradation. Antarct Sci., 20, 463-470.

[23] Bradner J. R., Gillings M., Nevalainen K. H. M. (1999). Qualitative assessment of hydrolytic activities in Antarctic microfungi grown at different temperatures on solid media. World J Microb Biot., 15, 131-132.

[24] Chlebicki A. (2009). Some endophytes of Juncus trifidus from Tatra Mts. in Poland. Acta Mycol., 44, 1, 11-17.

[25] Tarroum M., Ben Romdhane W., Mohamed Ali A. A., Al-Qurainy F., Al-Doss A., Fki L., Hassairi A. (2021). Harnessing the Rhizosphere of the Halophyte Grass Aeluropus littoralis for Halophilic Plant-Growth-Promoting Fungi and Evaluation of Their Biostimulant Activities. Plants, 10, 784, 1-17.

[26] Gashgari R., Gherbawy Y., Ameen F. \& Alsharari S. (2016). Molecular Characterization and Analysis of Antimicrobial Activity of Endophytic From Medicinal Plants in Saudi Arabia. Jundishapur J Microbiol., 9, 1, e26157.

[27] Bickford W. A., Bourke K. A., Clay K., Kowalski K. P., Shearin Z. R. C. (2016). Diversity of fungal endophytes in nonnative Phragmites australis in the Great Lakes. Biol Invasions, 18, 2703-2716.

[28] Soares M. A., Li H. Y., Kowalski K. P., Bergen M., Torres M. S. \& White J. F. (2016). Evaluation of the functional roles of fungal endophytes of Phragmites australis from high saline and low saline habitats. Biol Invasions, 18, 9, $2689-2702$.

[29] El-Morsy E. M. (2000). Fungi isolated from the endorhizosphere of halophytic plants from the Red Sea Coast of Egypt. In: Aquatic Mycology across the Millennium. Fungal Diversity, 5, 43-54.

[30] Pandey P. K., Singh S., Yadav R. N. S., Singh A. K. and Chandra Kumar Singh M. (2014). Fungal endophytes: promising tools for pharmaceutical science. International Journal of Pharmaceutical Sciences Review and Research, 25, 2, $128-138$.

[31] Hala M. O. R., Adel A. E., Hassaan A. E., Samed A. D. (2010). Production, optimization and partial purification of lipase from Fusarium oxysporum. Journal of Applied Sciences in Environmental Sanitation, 5, 39-53.

[32] Katoch M., Aseem S., Gurpreet S. (2014). Endophytic fungi found in association with Bacopa monnieri as potential producers of industrial enzymes and antimicrobial bioactive compounds. Brazilian Archives of Biology and Technology, 57, 714-722.

[33] Abdel-Azeem A. M. \& Salem Fatma M. (2012). Biodiversity of laccase producing fungi in Egypt. Mycosphere, 3, 6, 900920.

[34] Abdel-Azeem A. M., Gherbawy Y. A. \& Sabry A. M. (2016). Enzyme profiles and genotyping of Chaetomium globosum isolates from various substrates. Plant Biosystems, 150, 3, 420-428. 